\title{
Corrosion resistance dry building mortars base on alkaline slag binder for using in aggressive sulfate medium
}

\author{
Vadim Turchin ${ }^{1}$, Stanislav Sychugov ${ }^{2}$, Ludmila Yudina ${ }^{3}$, Alexander Gumeniuk ${ }^{4}$, \\ Tatyana Zhilkina ${ }^{5}$, Yuriy Gmizov ${ }^{6}$, Rimantas Mackevicius ${ }^{7}$, Tatyana Ivanova ${ }^{8}$ \\ 1, 3, ${ }^{8}$ LLC Stroy-Exspert (Building Engineering Company), The 50-years of AULYCL 31, 426000 Izhevsk, Russia \\ ${ }^{2,4}$ Department of Constructional Materials, Mechanization and Geo-Engineering, V.A. Shumilov Institute of \\ Construction and Architecture, Izhevsk State Technical University named after M.T. Kalashnikov, \\ Studencheskaya str. 7, 426069 Izhevsk, Russia \\ ${ }^{5}$ Moscow State University of Civil Engineering (National Research University), Yaroslavskoe highway, 26, \\ 129337 Moscow, Russia \\ ${ }^{6}$ LLC Electroindustriya (Building Engineering Company), Mayskaya Str., 51, 426011 Izhevsk, Russia \\ ${ }^{7}$ Department of Geo-Engineering, Vilnius Gediminas Technical University, Vilnius, LT10223, Lithuania \\ E-mail: ${ }^{1}$ vadim@astek.izhnet.ru (corresponding author)
}

\begin{abstract}
Dry Building Mortars (DBM) are new in terms of building technology, and they sometimes substitute different kinds of concrete and mortar mixes. DBM have been successfully used in construction and their performance has been as efficient as the one of commercial mortar mixes, i.e. they boost labour efficiency, and bring down material consumption. They can be also kept in stock for a long time, and shipped with no compromise in quality. Today DBM are based on cementing components. And some famous mix mortars are based on gypsum, polymer, and some other types of cementing components which contain fine-dispersed additives of ground slag, fly ash, and raw sludge. These mix mortars are applied as smoothing, aligning, waterproof, and safety types of coverage.

This article studies the possibility of involving slag cementing components in manufacturing DBM. Due to their high waterproof resistance in salt-affected water, these sorts of mixes may be used as protective coatings and plasters for concrete frames in corrosive medium. Slag Cementing Components (SCC) are hydraulic cementing agents, which harden both in water and in open air. They are produced by mixing electric-furnace slag or furnace clinkers with some solutions of alkaline metals (to trigger alkaline reaction), or by mixing together all these agents.
\end{abstract}

Keywords: dry building mortars, electric-furnace slag, alkali silicate, sodium hydrate, slag cementing components, aggressive sulphate medium, ettringite, thaumasite, slag-alkaline binders.

\section{Introduction}

Cement products and constructions are attacked by corrosion. It decreases their mechanical properties and ends up in destruction. Concrete loses its performance characteristics due to crystallization of slightly soluble salts, as these swell up and put significant strain onto walls of stems. Another type of this corrosion is concrete destruction in sulfate medium. Sulfate corrosion appears while sulfates and cement aluminous mixtures (mostly containing $\mathrm{C}_{3} \mathrm{~A}$ ) merge into chemical interaction. Initial products become $2-2.5$ bigger once gone through interaction. These products are ettringite and thaumasite. They may be formed in a crystallizing mixture, as concrete constructions and products are used in places with drastic changes of temperature.

Slag cementing components (SCC) are one of the most affordable cementing components. They are resistant to being run in aggressive sulphate medium (Bazhenov, Korovyakov, \& Denisov, 2011; Runova, Konstantinovskiy, \& Rudenko, 2011). The scientific researches of Glukhovsky, Moskvin, Alekseev and Ivanov, which are devoted to study corrosion resistance of cement stone base on alkaline slag binder in aggressive sulfate medium (Glukhovsky \& Pakhomov, 1978; Moskvin \& Royak, 1962; Alekseev, Ivanov, Modry, \& Schiessel, 1990; Ivanov, 1982) were continued by present authors. This article is aimed at developing formulas for corrosion resistant SCC, which could operate in aggressive kinds of medium. The authors have done a research in terms of sulphate resistance of artificial rock based on slag cementing components. The binding components were produced out of soluble glass and electric-

(C) 2019 Authors. Published by VGTU Press. This is an open-access article distributed under the terms of the Creative Commons Attribution (http://creativecommons.org/licenses/by/4.0/) License, which permits unrestricted use, distribution, and reproduction in any medium, provided the original author and source are credited. 
furnace slag. Aqua solution of sodium hydrate was taken to reach a faster hardening process. Hereinafter the authors give practical recommendations for applying SCC in building operations (Line, Dove, Knight, \& Winkler, 1996).

\section{Materials and research methods}

\section{Materials}

To produce SCC, we used the following components: electric-furnace slag of metallurgical production in the city of Izhevsk, and soluble sodium glass with a silicate module of 2.6 and density of $1.21 \mathrm{~g} / \mathrm{cm}^{3}$. Also, to decrease the silicate module and increase water resistance of SCC an alkali solution $\mathrm{NaOH}$ (with a $10 \%$ weight flow) was simultaneously added. Electric-furnace slag was examined with XRD-analyze, and it was proved to be of an acid type (Figure 1).

Table 1. Particle size distribution test of granulated electric-furnace slag

\begin{tabular}{|c|c|c|c|c|c|c|c|c|c|}
\hline Mesh size, mm & $<0.16$ & 0.16 & 0.315 & 0.63 & 1.25 & 2.50 & 5.0 & $>5.0$ & Total \\
\hline $\begin{array}{c}\text { Content of fractions, \% } \\
\text { (partial residuals on mesh) }\end{array}$ & 25.8 & 5.0 & 36.5 & 21.7 & 9.0 & 0.6 & 9.0 & 0.5 & 100 \\
\hline
\end{tabular}

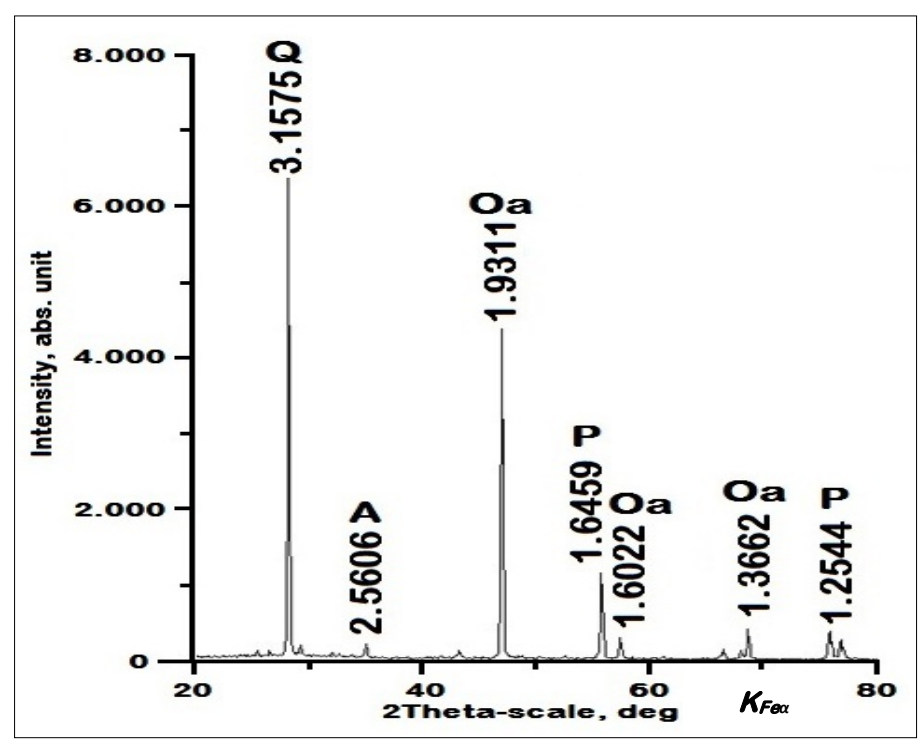

Figure 1. XRD of smelter slag: $\mathrm{P}-\mathrm{FeS}_{2}$ iron pyrite; $\mathrm{Oa}-\alpha-\mathrm{Al}_{2} \mathrm{O}_{3}$ corundum; $\mathrm{Q}-\beta-\mathrm{SiO}_{2}$ cristobalite

The electric furnace slag endured a two-stage processing: magnetic separation and a two-stage shattering (Chumakov, 2011). In order to reach a finer fraction $(<1 \mathrm{~mm})$, the slag was crushed with a ball mill in a laboratory setting till its specific surface reached $300-350 \mathrm{~m}^{2} / \mathrm{kg}$. Simultaneously, scalping process for fraction residues dropped out pieces of $0-5 \mathrm{~mm}$. Their grain content is shown in the Table 1. Mineralogical content of slag is shown on the X-ray pattern (Figure 1). As we can see, the biggest part is crystal phase of a high temperature modification of silicon oxide - $\beta$-cristobalite and corundum, there are pyrites' traces left. The authors of the article proved efficient applying of the electric furnace slag (Krivenko, Pushkareva, Gotz, \& Koval'chuk, 2012; Yudina \& Yudin, 1995; Runova, Rudenko, \& Konstantynovskyi, 2012; Yudina \& Turchin, 2011; Turchin, Yudina, Ibatyllina, \& Sattarova, 2012). The dry mortar was mixed with distilled water with $\mathrm{pH}=7.0 \pm 0.01$.

\section{Mortar preparation, identification and testing}

The contents of slag cementing binding agents were thoroughly selected, so that the components varied within the following limits: electric furnace slag $(\mathrm{S})-100 \% ; \mathrm{NaOH}-10 \%$, sodium silicate (soluble glass) $\mathrm{Na}_{2} \mathrm{O} \cdot m \cdot \mathrm{SiO} 2$ $(\mathrm{AG})-15-25 \%$, distilled water $(\mathrm{W})-0 \ldots 6.5 \%$. Consumption of components and properties of slag cementing binding agents are given in the Table 2.

Dry mortars were mixed with a water solution of sodium silicate containing $10 \% \mathrm{NaOH}$. In order to reach a homogenous consistency, blending machine stirred the components for 3 minutes at least. The final mixture was molded into cube samples with their $20 \times 20 \times 20 \mathrm{~mm}$ side. These samples were marked and held in humid air medium for 24 hours, and they then were subjected to steaming $2+4+2$ hours at temperature of isothermal time $\mathrm{T}=85 \pm 5^{\circ} \mathrm{C}$. 
Turchin, V.; Sychugov, S.; Yudina, L.; Gumeniuk, A.; Zhilkina, T.; Gmizov, Y.; Mackevicius, R.; Ivanova, T. 2019.

Corrosion resistance dry building mortars base on alkaline slag binder for using in aggressive sulfate medium

Table 2. The dry mortar compositions based on SAB, parts

\begin{tabular}{|c|c|c|c|c|c|c|c|c|}
\hline \multirow{2}{*}{ No } & \multicolumn{4}{|c|}{ Mortar Compositions, parts } & \multirow{2}{*}{$\begin{array}{c}\text { Density of } \\
\text { mortar, } \mathrm{g} / \mathrm{cm}^{3}\end{array}$} & \multirow{2}{*}{$\begin{array}{l}\text { Fluidity of } \\
\text { mortar, cm }\end{array}$} & \multirow{2}{*}{$\begin{array}{c}\text { Age of samples, } \\
\text { days }\end{array}$} & \multirow{2}{*}{$\begin{array}{c}\text { Time of testing } \\
\text { samples in aggressive } \\
\text { media, days }\end{array}$} \\
\hline & $\mathrm{S}$ & $\mathrm{NaOH}$ & $\mathrm{W}$ & $\mathrm{AG}$ & & & & \\
\hline 1 & 100 & 10 & 6.5 & 15 & 2.04 & 17.5 & \multirow{3}{*}{95} & \multirow{3}{*}{90} \\
\hline 2 & 100 & 10 & 2.5 & 20 & 2.09 & 17.3 & & \\
\hline 3 & 100 & 10 & - & 25 & 2.10 & 16.9 & & \\
\hline
\end{tabular}

For increasing speed reaction of calcium silicates hydration in samples of slag alcaline binder autoclave treatment was made (Glukhovsky, Krivenko, Starchuk, Pashkov, \& Chirkova, 1981; Bozhenov, 1978; Rozenfeld \& Neiman, 1968). Compression strength was defined by the samples that had been held in humid air medium and water medium. According to the methods, to estimate sulphate resistance of SCC a part of samples was placed in $1 N$ solution $\mathrm{Na}_{2} \mathrm{SO}_{4}$ and was kept for 7, 45, 90 days in it. Physical-mechanical research was carried through the "JEOL SEM JSTM-330" electron microscope. X-ray analysis was carried through the "DRON-3" X-ray diffraction meter. The infrared spectrum analysis was carried out by means of the infrared Fourier spectrometer «Spectrum 100», and differential thermal analysis was carried through the "Pyris DIAMOND TG/DTA" derivatograph. The temperature rose at speed of $10^{\circ} \mathrm{C}$ per minute.

\section{Result and discussions}

\section{Test of cube crushing strength}

Cube samples acquired a better robustness after adding extra alkaline agent (AG $+\mathrm{NaOH})$ into $\mathrm{SCC}$ (Figure 2a). It is useless to add more than $20 \%$ of alkaline in SCC, as it is rather expensive and does not guarantee an ultra durability.

Strength properties of cube samples based on SCC (hardening in water, aggressive sulphate and humid air medium) were thoroughly examined. It was revealed that the best hardening level is gained at keeping these samples in humid air conditions. This is because soluble glass is also a cementing agent and it hardens in humid medium. The cube samples were analysed and compared after pressing or keeping them in water and aggressive medium. It became obvious, that after being kept in sulphate corrosive medium, the cubes lost $1.5 \%$ of their durability level. The samples with $20 \%$ of alkaline component showed a good durability level, and the samples kept in humid air proved their ultimate resistance of $14 \mathrm{MPa}$. This alkaline content was chosen as the most appropriate one (Figure 2b).

Sulphate resistant samples of slag alkaline composition were externally estimated after they had been sunk and stored in $1 N$ solution $\mathrm{Na}_{2} \mathrm{SO}_{4}$ for 7, 45, 90 days. It was revealed that these samples did not endure any significantly structural changes, and they are therefore corrosion resistant in sulphate waters.

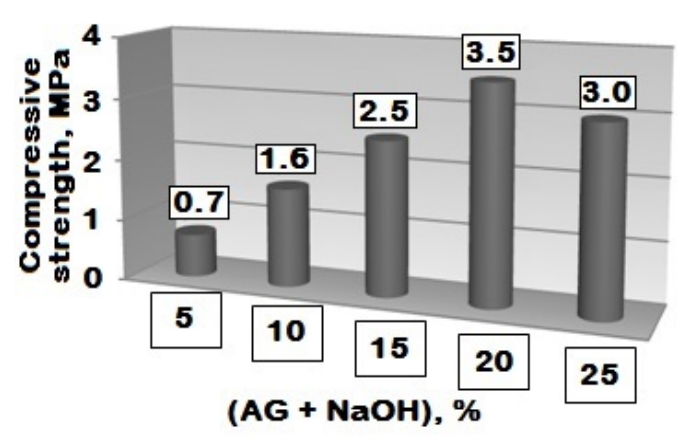

a)

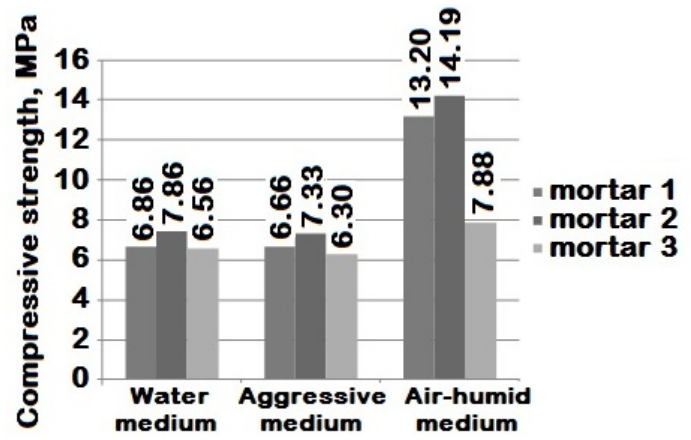

b)

Figure 2. Ultimate resistance depends on how pressed cement binding agents are:

(a) - content of alkaline ratio (for 7 days); (b) - keeping the samples in various medium (for 28 days)

We should also highlight, that silicate natrium's firmness is opportune for corrosion resistance. Insignificant corrosion resistance decrease is slightly changes strength level of the samples when pressed. But it also enables technological characteristics of the composition, such as homogeneity and plasticity. And this is very important for applying further protective coatings. Density level of the samples varied within the limits $2.2 \ldots 2.3 \mathrm{~g} / \mathrm{cm}^{3}$. According to their plasticity properties, these compositions belong to the brand mixtures PK 8 (which is an average plasticity level to immerse a standard metal cone of $4 . . .8 \mathrm{~cm}$ deep). 


\section{Physicochemical analysis}

We made a physical-chemical analysis to define the best composition No 2, which had been held in humid-air, water, and aggressive medium. Analcime $\mathrm{Na}\left[\mathrm{AlSi}_{2} \mathrm{O}_{6}\right] \times \mathrm{H}_{2} \mathrm{O}$ (water aluminum sodium silicate) is the key component for reaching ultra hardening level in humid air conditions in terms of artificial stone based on SCC. After being stored in isothermal time, in humid and alkaline medium (Gorshkov, Savel'ev, \& Abakumov, 1994), it easily acquires crystal formations in pore space of artificial stone. This is what microscopic investigations reveal (Figure 3a, b). The micrographs precisely show tetragonal crystals of analcime (they are marked with an arrow), and at zooming we can see tiny plate-like formations of sodium silicate. The data of the microstructure is proved by the research accomplished with X-ray phase analysis (Figure 3c), where analcime shows diffractions $\mathrm{d}_{\alpha}=(2.5606$; 2.1717; $2.0919 \AA$ ) close to the corners 2Theta $=35-43^{\circ}$ (Yokomori \& Idaka, 1998; Phillips \& Kirkpatrick, 1994; Gorshkov et al., 1994).

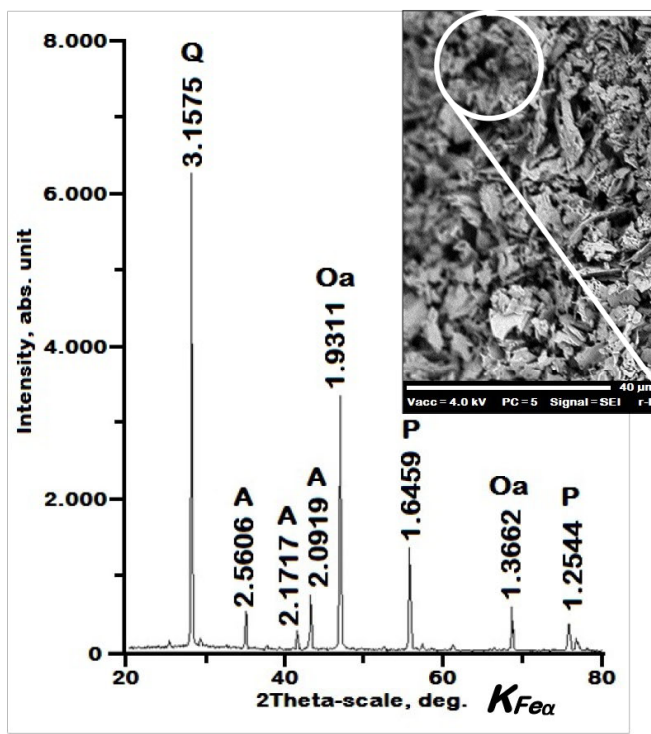

a)

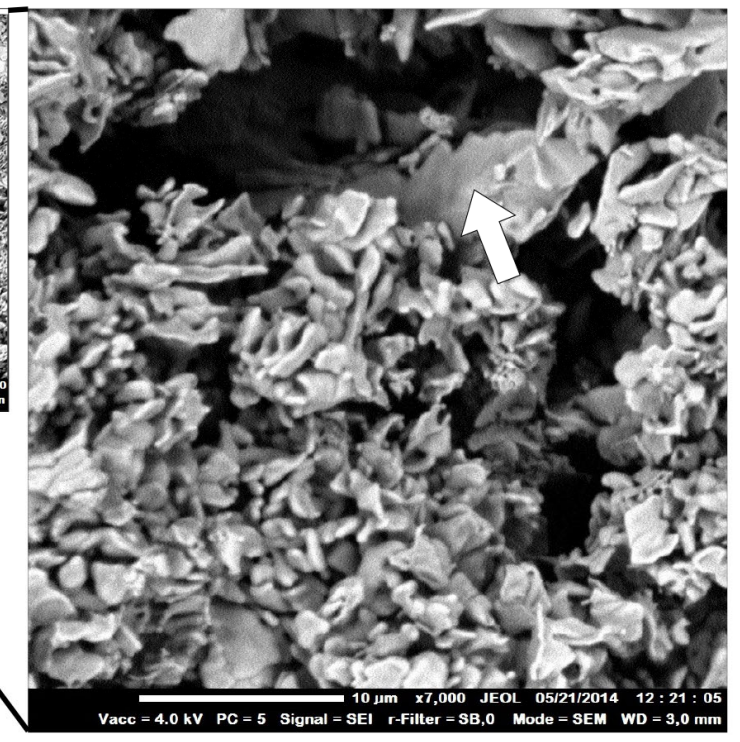

c)

Figure 3. Physical and chemical examinations on the composition No 2 of SCC, after being kept in humid air medium are the following: (a) - X-ray pattern ( $\mathrm{A}$ - analcime; $\mathrm{Q}-\beta-\mathrm{SiO}_{2}$ cristobalite; $\mathrm{Oa}-\alpha-\mathrm{Al}_{2} \mathrm{O}_{3} ; \mathrm{P}$ - pyrites $\mathrm{FeS}_{2}$ ); microstructure:

(b) - at 2500 multiply enlargement (analcime is marked with an arrow); (c) - at 7000 multiply enlargement

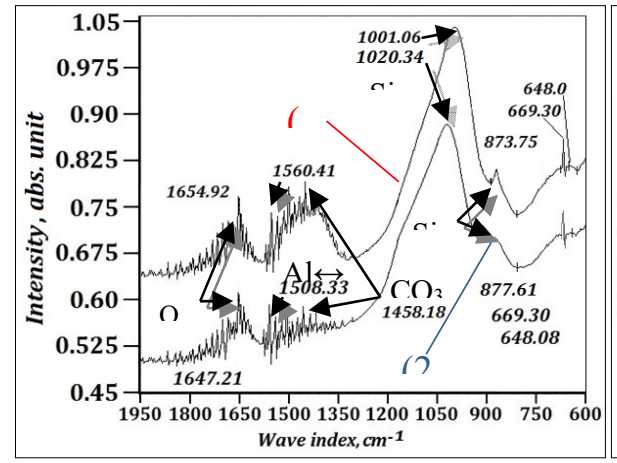

a)

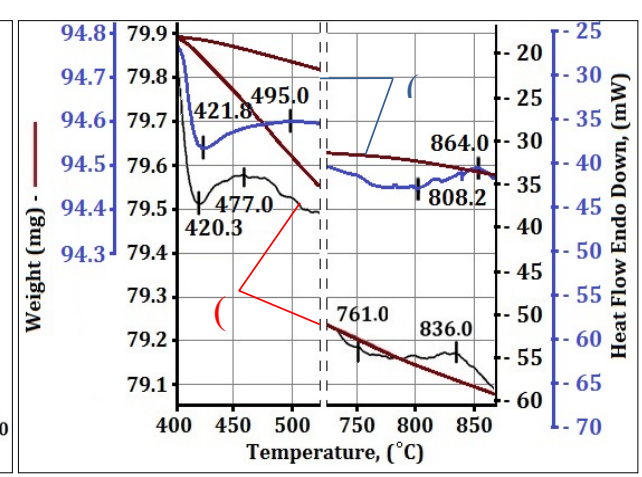

b)

Figure 4. Physical and chemical examinations of samples, after being kept in humid air (1) and aggressive (2) medium are the following: (a) - infrared spectrum; (b) - thermogram

The infrared spectrum analysis and differential thermal analysis also demonstrate analcime component. Infrared spectrum (Figure 4a) shows stretching vibrations of water molecules at frequency of $1654.92 \mathrm{~cm}^{-1}$, which are typical for water aluminum silicates of analcime type. Its crystalline modification and acquiring a stable structure give a clue to stretching vibrations linking $\mathrm{Si}-\mathrm{O}$ in silicon oxygen tetrahedral unit at $1001.06 \mathrm{~cm}^{-1}$ and $873.75 \mathrm{~cm}^{-1}$ absorption frequencies, and along with deformation vibrations at an average frequency of $669.30 \mathrm{~cm}^{-1}$. 
The thermogram (Figure 4b) shows dehydration of analcime at the temperature of $420.3^{\circ} \mathrm{C}$. This is an endothermic effect, and the following effect is an exothermic one at $477.0^{\circ} \mathrm{C}$. This is because tetragonal analcime crystallizes into a cube-shaped one (Gorshkov, Timashev, \& Savel'ev, 1981; Gottardi \& Galli, 1985).

As analcime is formed throughout the pore space, there are always fewer pores left in the artificial rock based on SCC, and this rock gains a stable hardened structure. Although there are supposed to be certain destructions (experiment samples lose their strength as pore walls endure extra pressing at analcime crystallization), they never happen, since alkaline content $(\mathrm{AG}+\mathrm{NaOH})$ is quite limited, no more than $20 \%$.

Above all, the artificial rock based on SCC contains: a low temperature type of cristobalite $\beta-\mathrm{SiO}_{2}$ which has the only diffraction line $\mathrm{d}_{\alpha}=(3.1575 \AA)$; pyrites $\mathrm{FeS}_{2}$ and aluminum oxide $\alpha-\mathrm{Al}_{2} \mathrm{O}_{3}$ with its corresponding diffraction superior limits $\mathrm{d}_{\alpha}=(1.6459 ; 1.2544 \AA), \mathrm{d}_{\alpha}=(1.9311 ; 1.3662 \AA)$ (Gorshkov et al., 1994).

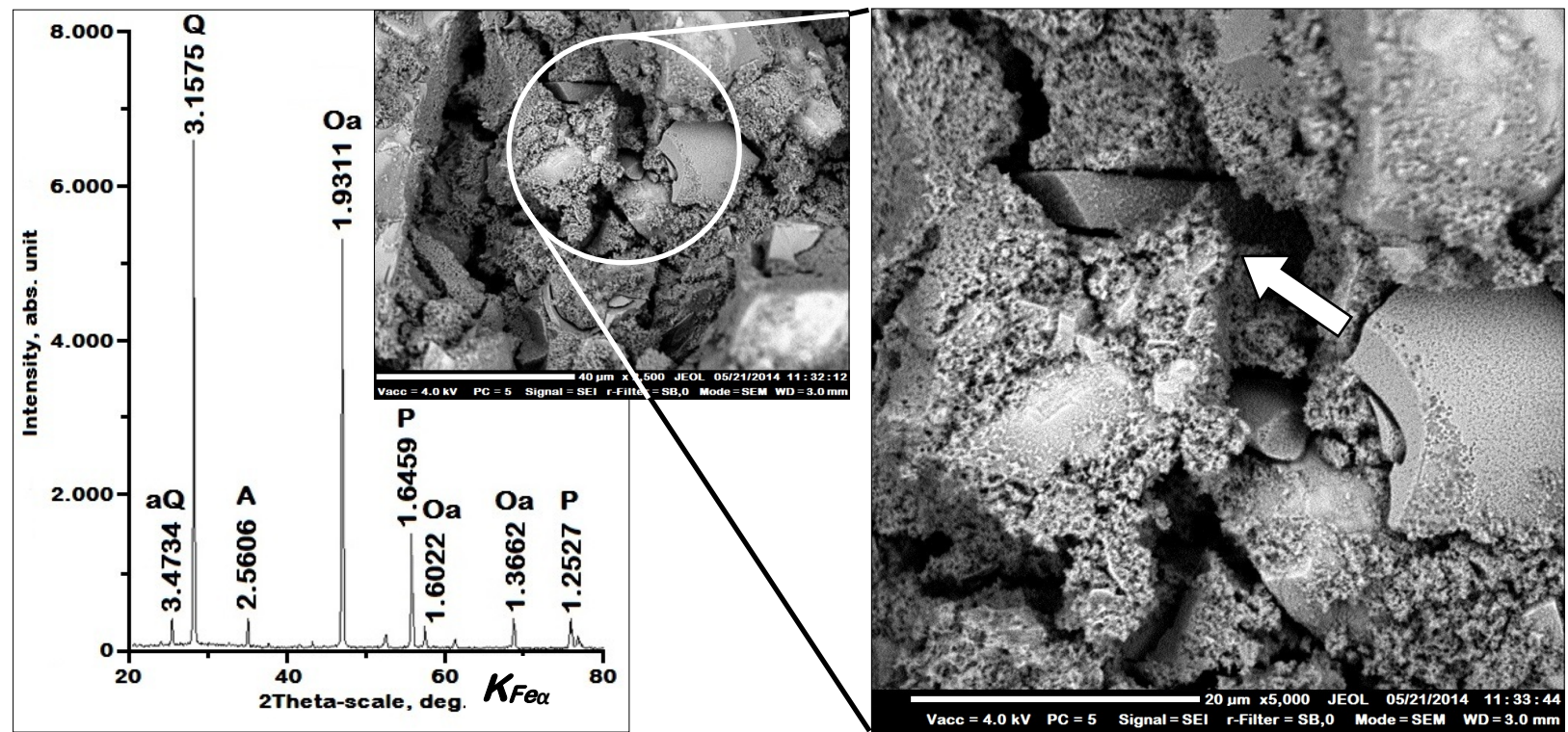

a)

b)

c)

Figure 5. Physical and mechanical research of the SCC composition No 2, after its holding in water medium: (a) - X-ray pattern ( $\mathrm{A}$ - analcime; $\mathrm{Q}-\beta-\mathrm{SiO}_{2}$ cristobalite; $\mathrm{Oa}-\alpha-\mathrm{Al}_{2} \mathrm{O}_{3} ; \mathrm{P}-$ pyrites $\mathrm{FeS}$ ); microstructure: (b) - at 2500 multiply enlargement; (c) - at 5000 multiply enlargement (analcime is marked with arrows)

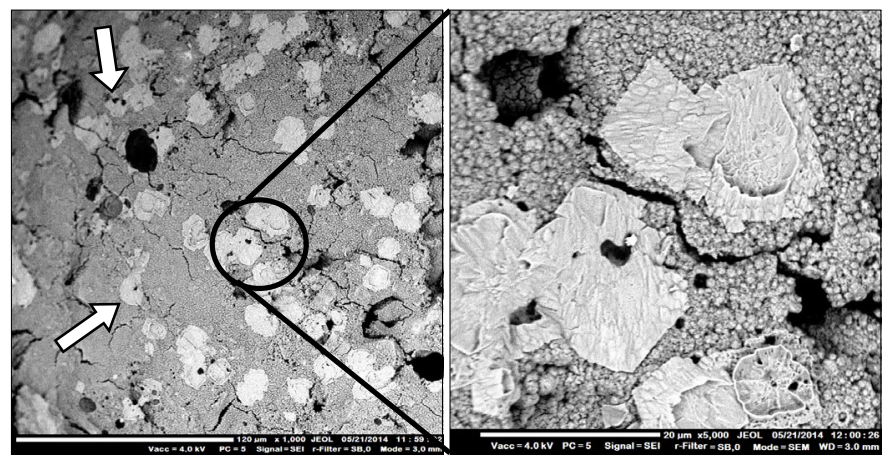

a)

b)

Figure 6. Surface microstructure of the sample composition No 2 on being kept in corrosive medium:

(a) - at 1000 multiply enlargement; (b) - at 5000 multiply enlargement (arrows show the leaching process of portlandit)

The SCC rock composition No 2 (the one hardening in water medium) was examined by means of destructive physical analysis (Figure 5a). It revealed a similar diffraction setting, as the one we mentioned earlier. The following components go apart: pyrites $\mathrm{FeS}_{2} \mathrm{~d}_{\alpha}=(1.6406 ; 1.2527 \AA)$; cristobalite $-\beta-\mathrm{SiO}_{2} \mathrm{~d}_{\alpha}=(3.1575 \AA)$ and quartz $\alpha-\mathrm{SiO}_{2}$ $\mathrm{d}_{\alpha}=(3.4734 \AA)$; corundum $\mathrm{d}_{\alpha}=(1.9311 ; 1.6022 ; 1.3662 \AA)$. Corundum tends to be more diffracted, since it is unevenly spread in the electric furnace slag. It was ascertained, that amplitude of diffraction superior limits $\mathrm{d}_{\alpha}=$ $(2.5606 \AA)$ of analcime $\left(\mathrm{Na}\left[\mathrm{AlSi}_{2} \mathrm{O}_{6}\right] \times \mathrm{H}_{2} \mathrm{O}\right)$ around the angles $2 \mathrm{Theta}=35-40^{\circ}$ drastically decreased, and there were no diffractions at the range $\mathrm{d}_{\alpha}=(2.1717 ; 2.0919 \AA)$. Thus, it can be claimed that analcime is formed less in the rock 
based on SCC, due to washing out of the alkaline component. Apart from hexaoctahedral crystals of analcime (they are marked with an arrow, Figure 5a, b), the rock contains an exuberant content of slag and a small content of binding agent, as micrographs show (Figure 5c). There is an elusive adhesion of the binding agent and the slag; this is why experiment samples are not cemented enough (Figure 2b). After being kept in water medium, the rock has numerous pores, as alkaline component $(\mathrm{AG}+\mathrm{NaOH})$ was washed out.

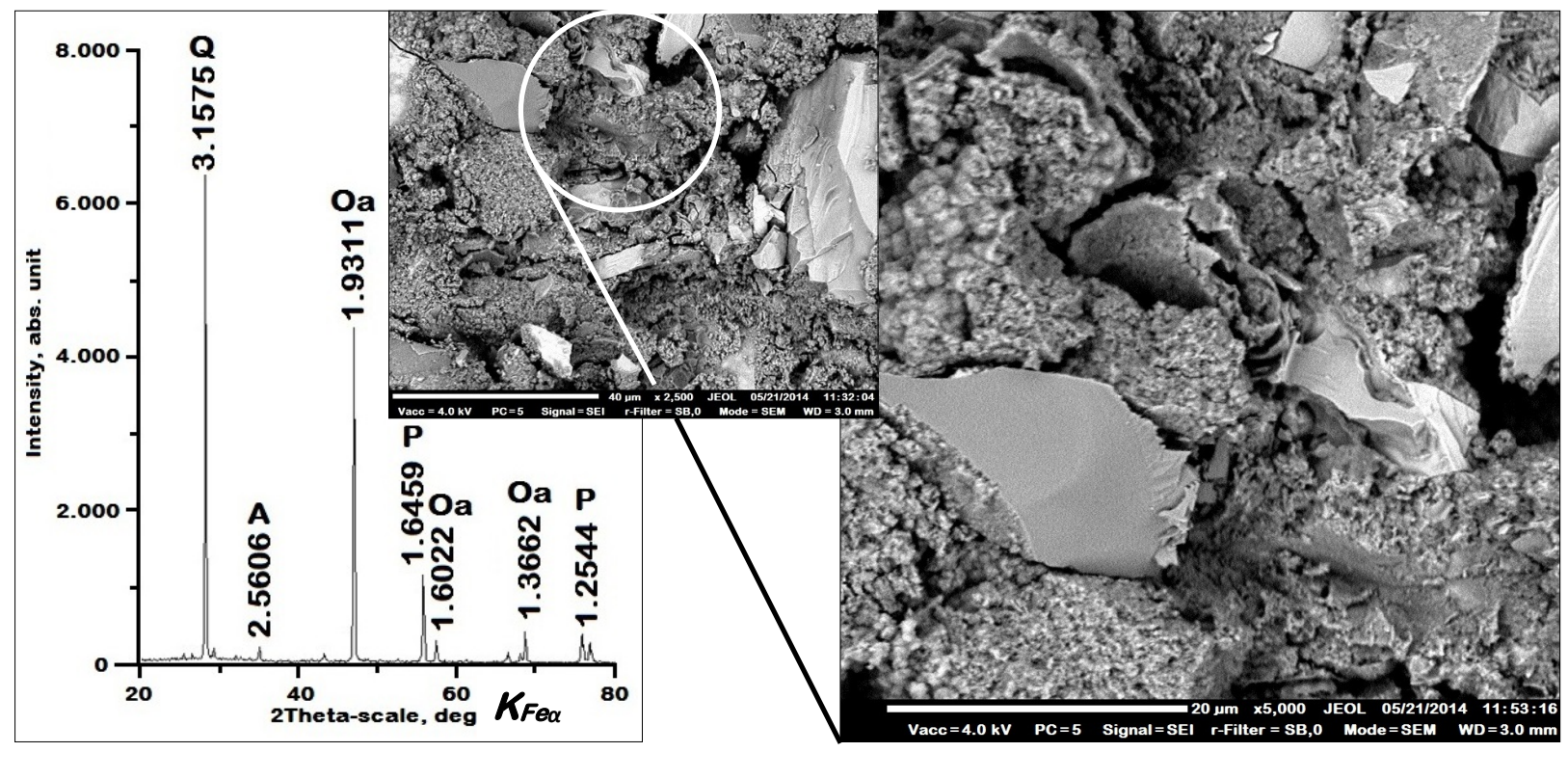

a)

b)

c)

Figure 7. Physical and chemical research of the SCC composition No 2, held in corrosive sulfate medium: (a) - X-ray pattern ( $\mathrm{A}$ - analcime; $\mathrm{Q}-\beta-\mathrm{SiO}_{2}$ cristobalite; $\mathrm{Oa}-\alpha-\mathrm{Al}_{2} \mathrm{O}_{3} ; \mathrm{P}$ - pyrites $\left.\mathrm{FeS}_{2}\right)$; microstructure: (b) - at 2500 multiply enlargement; (c) - at 5000 multiply enlargement

After the artificial rock based on SCC was put and stored in aggressive sulfate medium, some efflorescence appeared on the surface of the experiment samples. After examining micrographs of the artificial rock's spalls, we saw new-formed tabular crystals of sodium sulphate decahydrate $\mathrm{Na}_{2} \mathrm{SO}_{4} \times 10 \mathrm{H}_{2} \mathrm{O}$ (Figure $6 \mathrm{a}, \mathrm{b}$ ). And this is despite the fact that meticulous investigations by means of destructive physical analysis, differential thermal analysis and the infrared one had denied any salt components in artificial rock content. The X-ray pattern demonstrated no diffractions related to sodium sulfate decahydrate $\mathrm{Na}_{2} \mathrm{SO}_{4} \times 10 \mathrm{H}_{2} \mathrm{O}$ (Figure 7a). Besides, the X-ray pattern shows no fractions of the following components: pyrites $\mathrm{FeS}_{2} \mathrm{~d}_{\alpha}=(1.6459 ; 1.2544 \AA)$; cristobalite $\beta-\mathrm{SiO}_{2} \mathrm{~d}_{\alpha}=(3.1575 \AA)$; aluminum oxide $\mathrm{d}_{\alpha}=(1.9311 ; 1.6022 ; 1.3662 \AA)$ and analcime $\left(\mathrm{Na}_{2}\left[\mathrm{AlSi}_{2} \mathrm{O}_{6}\right] \times \mathrm{H}_{2} \mathrm{O}\right) \mathrm{d}_{\alpha}=(2.5606 \AA)$. However, comparison study of analcime density always proves to be low in the last case, where the sample No 2 was held in corrosive sulfate medium. Alkaline agent and acid solution $\mathrm{Na}_{2} \mathrm{SO}_{4} \times 10 \mathrm{H}_{2} \mathrm{O}$ interact and contribute to alkaline destruction. While alkaline agent is being destructed, it is setting off silicon oxide as an amorphous deposit. Since the solution pH-drawing is lowering towards acid medium (Butt, Okorokov, Sychev, \& Timashev, 1965; Manevich, Subbotin, \& Efremenkov, 2011; Cruciani \& Gualtieri, 1999). Analcime slowly crystallizes in the medium. As a result of filling pore space with amorphous silicon dioxide, the structure has a better hardening level and fewer flaws in its total amount (Figure 7c).

A compare study of the thermograms (Figure $4 \mathrm{~b}$ ) (especially in terms of shapes and surface of thermal effect spikes, typical for dehydrated analcime) reveal its insignificant content in the artificial rock, and it reached its temperature peak $421.8^{\circ} \mathrm{C}$. Tetragonal analcime crystallizes and steadily turns into a cube-shaped one (Figure $6 \mathrm{~b}$ ). Due to new formations, its temperature peak went up till $495.0^{\circ} \mathrm{C}$. Crystallizing process of amorphous silica (residues) at $864.0^{\circ} \mathrm{C}$ provokes exothermic effect. The thermograph shows no effects related to new formed agents. This is also proved by destructive physical analysis.

The infrared spectrum analysis (Figure 4a) of the sample that had been kept in corrosive sulfate medium, contained no new formed agents. A strong absorption band at frequency $1020.34 \mathrm{~cm}^{-1}$ and a weak absorption band at $877.61 \mathrm{~cm}^{-1}$ are typical for stretching vibrations of the combination $\mathrm{Si}-\mathrm{O}$, and the frequency $1647.21 \mathrm{~cm}^{-1}$ causes stretching vibrations of water molecules in sheet silicates content. There is an evident shift of meaning towards high frequency at $19.28 \mathrm{~cm}^{-1}$ and $3.86 \mathrm{~cm}^{-1}$ in the first case and towards low frequency at $7.71 \mathrm{~cm}^{-1}-$ in the second case. This is because new components are formed in the artificial rock under corrosive tests, and their crystal pattern changes its dimensional characters (Figure 4a). A narrow absorption band at $669.30 \mathrm{~cm}^{-1}$ gives evidence of 
deformation vibrations of the combination $\mathrm{Si}-\mathrm{O}$. Faint reflections with a frequency of $648.08 \mathrm{~cm}^{-1}$ lead to stretching vibrations of the combination $\mathrm{Si}-\mathrm{O}$ in silicon dioxide.

Thus, comparative results of physical and chemical analysis of the SCC samples of the composition No 2, that had gone through corrosive tests proved no evidence of new formations that might destroy the artificial rock.

\section{Recommendations to practical use}

According to the All-Union Standard (GOST 31189) dry mortars based on SCC refer to special-purpose water protective mixtures of surface type. These mixtures are aimed to protect surface of concrete and reinforced concrete constructions to boost up their ultimate resistance to sulfate aggressive medium.

The application technology for dry mortars based on SCC is similar to the application technology for acidresisting cement. The mortars are delivered to construction sites as powder produced out of grained slag and additives. On constructions sites these mortars are mixed with sodium silicate for a smoother laying and aligning. The mixture is applied onto a surface by hand. Once hardened, it is always better to apply an extra hydro protective layer made of bitumen coating mastic.

\section{Conclusions}

In the light of examined Russian and international researches' data and experimental tests, we have proved efficient usage of the slag as filler in slag cementing components.

Physical tests revealed that the best hardening level is possible when the alkaline component's content is $20 \%$ (it consists of soluble glass and sodium hydrate), and humid air medium is the best to reach this percentage.

The best SCC composition is the one No 2 consisting of (\%): alkaline component (\%): soluble glass -20 and $\mathrm{NaOH}-10$; electric furnace slag -100 ; water $-2.5 \%$.

By means of the destructive physical analysis, crushing and grading complex, infrared spectrum analysis and microscopic examinations, analcime new formations are evident, no matter what the samples' storage conditions are. Water aluminum silicate refers zeolite group and it has a small level of solubility. Analcime component enables the samples' strength.

It is also proved that a significant strength decrease of the compositions based on SCC goes through water medium, as alkaline component becomes dehydrated.

The results of complex physical and chemical examination of the rock based on SCC demonstrate no ettringite and no gypsum in the samples' structure. It is utterly important, as gypsum and ettringite are the main reason for destroying materials based on Portland cement under sulfate corrosive conditions.

Scientific and experimental research of the rock based on SCC demonstrated its resistance to corrosive attack in sulfate corrosive medium $\left(1 \mathrm{~N}\right.$ solution $\left.\mathrm{Na}_{2} \mathrm{SO}_{4}\right)$. This is why this type of rock may be applied as a protective coating for concrete constructions.

The developed dry building mortars are based on slag cementing components and they meet technical requirements for dry building mixes. The technology for their application is simple and does not involve any special equipment. Its improved corrosion resistance makes it possible to use these mortars in sulfate corrosive medium.

\section{Acknowledgements}

The authors of this article show gratitude to the employee of the «Research of Polymer Materials and Plastics» laboratory of the OJSC «Izhevsk Plastics Factory» Kasimov I. A. and to the Doctor of Physics and Mathematics, laboratory chief «Mechanical Activation of Organic Systems» Kanygin G. N.

\section{References}

Alekseev, S. N., Ivanov, F. M., Modry, S., \& Schiessel, P. (1993). Durability of reinforced concrete in aggressive media (Russian translations series 96). A. A. Balkema.

Bazhenov, Y. M., Korovyakov, V. F., \& Denisov, G. A. (2011). The technology of dry building mortars. ACB. Moscow.

Bozhenov, P. I. (1978). Autoclave materials technology. Leningrad: Stroyizdat.

Butt, Yu. M., Okorokov, S. D., Sychev, M. M., \& Timashev, V. V. (1965). Technology of binding substances. Moscow: Vysshaya Shkola Publishers.

Chumakov, L. D. (2011). The technology of concrete aggregate. ACB. Moscow.

Cruciani, G., \& Gualtieri, A. (1999). Dehydration dynamics of analcime by in situ synchrotron powder diffraction. American Mineralogist, 84(1-2), 112-119. https://doi.org/10.2138/am-1999-1-212

Glukhovsky, V. D., Krivenko, P. V., Starchuk, V. N., Pashkov, I. A., \& Chirkova, V. V. (1981). Slag alkaline concretes made with fine aggregates. Kiev: Vysshaya Shkola Publishers.

Glukhovsky, V. D., \& Pakhomov, V. A. (1978). Slag-alkaline cements \& concretes. Kiev. 
Turchin, V.; Sychugov, S.; Yudina, L.; Gumeniuk, A.; Zhilkina, T.; Gmizov, Y.; Mackevicius, R.; Ivanova, T. 2019.

Corrosion resistance dry building mortars base on alkaline slag binder for using in aggressive sulfate medium

Gorshkov, V. S., Savel'ev, V. G., \& Abakumov, A. V. (1994). Binders, ceramics and glassy-crystalline materials: Structure and properties. Moscow: Stroyizdat.

Gorshkov, V. S., Timashev, V. V., \& Savel'ev, V. G. (1981). The methods of physico-chemical analyze of binding materials. Moscow: Stroyizdat.

Gottardi, G., \& Galli, E. (1985). Natural zeolites. Springer-Verlag, Berlin. https://doi.org/10.1007/978-3-642-46518-5

Ivanov, F. M. (1982). On modelling of corrosion processes of concrete. Concrete and Reinforced Concrete, 7, 45-46.

Krivenko, P. V., Pushkareva, E. K., Gotz, V. I., \& Koval'chuk, G. Yu. (2012). Cements and concretes based on fuel ashes and slags. Kiev: IPK Express-Poligraf.

Line, C. M. B., Dove, M. T., Knight, K. S., \& Winkler, B. (1996). The low-temperature behavior of analcime: 1. High-resolution neutron powder diffraction. Mineralogical Magazine, 60(400), 499-507. https://doi.org/10.1180/minmag.1996.060.400.11

Manevich, V. E., Subbotin, K. Yu., \& Efremenkov, V. V. (2011). The raw materials, furnace charge and glass melting. Moscow: Stroimateriali.

Moskvin, V. M., \& Royak, G. S. (1962). Corrosion of concrete under the action of cement alkalis on silica filler. Moscow: Stroyizdat.

Phillips, B. L., \& Kirkpatrick, R. J. (1994). Short-range Al-Si. Order in leucite and analcime: determination of the configurational entropy from $27 \mathrm{Al}$ and variable-temperature $29 \mathrm{Si}$ NMR spectroscopy of leucite, its Cs- and Rb-exchanged derivatives, and analcime. American Mineralogist, 79, 1025-1031.

Rozenfeld, L. M., \& Neiman, A. G. (1968). Cement-free gas-slag concrete. Moscow: Stroyizdat.

Runova, R. F., Konstantinovskiy, A. P., \& Rudenko, I. I. (2011). Efficiency of using slag-alkaline cements in the production of dry mixtures. ALITinform: Cement. Concrete. Dry Mixtures, 2(19), 92-104.

Runova, R. F., Rudenko, I. I., \& Konstantynovskyi, O. P. (2012). Influence of chemical admixtures on characteristics of heatcorrosion resistant masonry mortars based on slag alkaline cements. In Conference: 18. Ibausil. Internationale Baustofftagung (vol. 1, pp. 1087-1094). Weimar, Germany.

Turchin, V. V., Yudina, L. V., Ibatyllina, A. R., \& Sattarova, A. R. (2012). Enhancement of sulphate resistance of cement containing composition due to crystallization of nano-phases. Intelligence Systems in Production, 2(20), 173-180.

Yokomori, Y., \& Idaka, S. (1998). The crystal structure of analcime. Microporous and Mesoporous Materials, 21(4-6), 365-370. https://doi.org/10.1016/S1387-1811(98)00019-5

Yudina, L. V., \& Turchin, V. V. (2011). Slag alkaline composition for building structures. In $4^{\text {th }}$ International Conference: NonTraditional Cement \& Concrete (pp. 4-8). Brno.

Yudina, L. V., \& Yudin, A. V. (1995). Metallurgical and fuel slags in building production. Udmurtiya, Izhevsk. 